\title{
Makna Nilai Budaya Masyarakat Palembang Pada Busana Aesan Gede
}

\author{
Desi Lestari ${ }^{1}$, Hudaidah $^{2}$ \\ ${ }^{1,2}$ Universitas Sriwijaya \\ desileestari@gmail.com \\ hudaidah@fkip.unsri.ac.id
}

\begin{abstract}
Abstrak
Budaya merupakan hal mendasar yang terdapat dalam kehidupan, sebab kebudayaan adalah mutlak terlahir dari kehidupan manusia sehari-hari. Pada budaya masyarakat Kota Palembang terdapat pakaian pengantin yaitu Aesan Gede yang merupakan hasil perpaduan budaya Kerajaan Sriwijaya yang masih tetap eksis sampai masa kini. Aesan Gede bukan hanya sebatas pakaian adat biasa namun memiliki nilai didalamnya. Tujuan penelitian ini hendak mengungkap makna nilai budaya seperti apa yang terkandung pakaian adat Palembang Aesan Gede. Adapun metode yang dipergunakan yaitu studi kepustakaan untuk mengupas tentang makna nilai budaya Palembang yang terdapat dalam busana Aesan Gede. Bentuk gaun pengantin Aesan Gede terbagi atas kepala, badan, tangan dan kaki. Fungsi busana Aesan Gede memiliki dua fungsi, yaitu fungsi sebagai fungsi estetika, dan fungsi sebagai fungsi simbolik. Dalam hal ini Aesan Gede bukan hanya sebagai pakaian adat tetapi juga sebagai bentuk ekspresi masyarakat Palembang.
\end{abstract}

Kata Kunci: Nilai Budaya, Busana, Aesan Gede

\begin{abstract}
Culture is a fundamental thing in life, because culture is absolutely born from everyday human life. In the culture of the people of Palembang City, there is a wedding dress, namely Aesan Gede which is the result of a blend of the culture of the Sriwijaya Kingdom which still exists today. Aesan Gede is not only limited to ordinary traditional clothes but has value in it. The purpose of this study is to reveal the meaning of cultural values such as what is contained in the traditional clothing of Palembang Aesan Gede. The method used is a literature study to explore the meaning of Palembang cultural values contained in Aesan Gede clothing. The form of Aesan Gede's wedding dress is divided into the head, body, hands and feet. The function of Aesan Gede's clothing has two functions, namely a function as an aesthetic function, and a function as a symbolic function. In this case, Aesan Gede is not only a traditional dress but also a form of expression for the people of Palembang.
\end{abstract}

Keywords : Cultural Values, Clothing, Aesan Gede. 


\section{Pendahuluan}

Indonesia adalah negara kepulauan dengan letak strategis yang di batasi dua samudra dan dua benua membuatnya menjadi negara yang kaya baik dari segi ekonomi sosial dan budaya. Indonesia dengan ragam kebudayaan dari berbagai daerah menjadikannya sebagai negara multicultural dan memberi daya tarik lebih kepada wisatawan asing. Membahas mengenai budaya tak akan luput dengan unsur seni di dalamnya. Seni sendiri merupakan hasil produk dari rasa, cipta dan karsa manusia yang tertuang dalam suatu karya yang bernilai dan memiliki keindahan. Suatu karya yang tercipta akan mengandung nilai yang ada dalam kehidupan. Dalam karya seni, nilai yang terkandung berupa wujud cerminan sikap dari manusia yang menciptakannya. Manusia sendiri merupakan makhluk yang membutuhkan seni dan budaya dalam kehidupan sehari-hari. Sebab manusia mempunyai kebutuhan akan nilai estetik (keindahan) yang disebut dengan kebutuhan intergraf. Kebutuhan integraf merupakan kebutuhan yang timbul sebab adanya keinginan dari diri untuk mengklaim bahwa manusia memiliki hak, moral, berakal dan memiliki cita rasa (Rohidi, 2008: 28).

Menurut pendapat Marwiyah (2010: 62), manusia pastinya membutuhkan pakaian sebagai pelindung tubuh dalam beraktivitas sehari-hari, yang kemudian diberi nilai estetika dalam pakaian tersebut sehingga pakaian mempunyai peran selain menutupi tubuh juga memberikan penampilan yang lebih baik dari sebelumnya. Pakaian dapat menunjukkan darimana seseorang berasal berdasarkan apa yang dipakainya dan hal ini menjadikannya sebagai bagian dari jati diri manusia

Pakaian yang di gunakan bersifat menunjukkan status sosial si pemakai dan dapat menunjukkan kepribadian bangsa. Selain dari itu, Pakaian juga dapat memberikan pesan atau image kepada orang yang akan melihatnya. Seperti halnya dengan Pakaian adat. Pakaian adat sendiri merupakan salah satu produk yang tercipta melalui pemikiran manusia yang menjadi lambang setiap daerah dan dijadikan tradisi turun temurun. Pakaian adat merupakan pakaian yang dimiliki oleh setiap daerah di Indonesia. Perbedaan budaya antar daerah di Indonesia dapat terlihat dari pakaian adatnya. Pakaian adat dalam konteks sosial dapat memberikan nilai kelarasan dan keharmonisan bagi tubuh manusia.

Menurut Dharmaika (1988: 16), pakaian adat merupakan pakaian yang dipakai secara turun-temurun dan menjadi identitas yang dapat dibanggakan oleh penganut 
kebudayaan tersebut. Disisi lain, pakaian adat mampu menyampaikan pesan mengenai nilai budaya yang terkandung pada simbol atau motif yang tercermin dalam pakaian adat tersebut (Saramat, 1997).

Dari kejayaan Kerajaan Sriwijaya hingga Kesultanan Palembang Darussalam, Palembang merupakan salah satu kota dengan sejarah yang panjang. Keberadaan kain songket di Palembang membuktikan tradisi Kerajaan Sriwijaya. Warna gemerlap dan cahaya keemasan pada Kain Songket memberikan nilai tersendiri dan memberikan nilai kehebatan bagi orang-orang yang membuat kain ini. Songket awalnya "Sungkit" dalam bahasa Melayu dan Indonesia yang artinya "menusuk". Sebab pada saat proses membuatnya yaitu dengan cara mengaitkan, kemudian mengambil kain tenun dan diselipkan dengan benang keemasan. Songket merupakan kain tenun yang bernilai mewah, dan biasanya dikenakan pada saat festival, hajatan maupun saat pesta.

Dalam pakaian pernikahan, Songket Palembang terbagi menjadi Aesan Gede dan juga Pak Sangkong. Keduanya pergunakan mempelai saat melakukan acara resepsi. Busana pernikahan adat Palembang ini meliputi aksesoris dasar hingga tambahan mengandung nilai simbolisme yang bermakna. Dari pembahasan singkat ini penulis tertarik untuk melakukan kajian guna menelaah arti makna yang terkandung.

Penelitian terdahulu yang sudah dilakukan yang berkaitan dengan penelitian di antaranya; Shanie, Sumaryanto, \& Triyanto (2017) tentang Busana Aesan Gede dan Ragam Hiasnya sebagai Ekspresi Nilai-Nilai Budaya Masyarakat Palembang. Ada hasil penelitian Hikmawati (2017) mengenai Makna Simbol dalam Aesan Gede dan Pak Sangkong Pakaian Adat Pernikahan Palembang. Kemudian penelitian Tifanny, Rizali, \& Rudiyanto (2019) yang berkaitan dengan Busana Pengantin Aesan Gede (Tenun Songket dan aksesoris) pada Upacara Pernikahan Adat Palembang Sumatera Selatan. Penelitian di atas tentu berbeda dengan penelitian ini dari aspek makna budayanya, karena itu urgensi penelitian ini dapat dipandang dari aspek budaya yang melekat pada busana Aesan Gede. Oleh karena itu keberbedaan penelitian ini dengan kajian di atas dapt dilihat pada aspek makna budaya pada pakaian adat tersebut.

\section{Metode Penelitian}

Penelitian ini menggunakan metode kepustakaan. Hampir semua dokumen (buku, artikel atau makalah) diklasifikasikan sebagai sumber sekunder (Zed, 2014). Secara 
umum, membaca buku dalam berbagai bidang merupakan gambaran dari informasi faktual dan gambaran penjelasan pandangan penulis (teori). Langkah-langkah yang dilakukan yaitu mengumpulkan bahan penelitian berupa buku dan artikel ilmiah terkait; membaca bahan pustaka; membuat catatan penelitian untuk menarik kesimpulan dari informasi yang diperoleh dari bahan bacaan tersebut; mengolah bahan bacaan tersebut kemudian menyusunnya dalam bentuk laporan penelitian.

\section{Pembahasan}

\section{Variasi Bentuk Aesan Gede sebagai Makna Nilai Budaya Masyarakat Palembang}

Aesan Gede merupakan busana pernikahan asli adat Palembang. Busana ini merupakan simbol yang agung, juga mencerminkan falsafah dan cara pandang, rasa tanggung jawab atas kehidupan, dan memiliki rasa kepemimpinan baik dalam bangsa, atau suku bangsa. Dalam fungsinya sendiri, Mutia (1996) Pakaian ini hanya diperbolehkan pada upacara tertentu yang bersifat sakral dan suci. Sebelumnya pengantin ini harus melewati beberapa upacara sakral untuk menjadi sepasang pasutri seperti : pilih calon, nyenggung, minang, rasanan, bekato-kato, ngantar duit belanjo, beraes, akad nikah, ngarak pacar, ngunduh mantu dan syukuran (Saragih, dkk., 2001).

Gaun Aesan Gede yang dikenakan oleh kedua mempelai merupakan satu kesatuan dan dapat digunakan sebagai pelengkap bagi kedua mempelai sebagai pasangan. Pakaian Aesan Gede yang dikenakan pria dan wanita hampir sama. Namun, istilah dan detail tiap bagian berbeda. Bentuk baju etan mempelai wanita berupa hiasan dari bagian atas (kepala) sampai bagian kaki (cendela). Pada kostum, bagian atas (kepala) berbentuk Bunga yang di kenal dengan Bungo Rampai dan bentuknya mirip dengan bunga krisan yang memiliki tangkai, namun bahannya keemasan, sedangkan bentuk Gandik adalah seikat yang terbuat dari kain beludru merah. Ikat kepala dengan bunga melati dekorasi di atas. Sedangkan untuk sanggul malu disebut dengan Gelung Malang, sanggul ini di buat dengan menggunakan rambut asli pengantin perempuan yang ditambahkan dengan serangkaian bunga mawar dan juga melati. Pada bagian kiri dan kanan kepala ditambahkan hiasan yang menjuntai dengan bentuk bola-bola berwarna warni, Untaian ini disebut dengan Tebeng Malu. Lain lagi dengan Kesuhun, kesuhun merupakan sebuah crown yang dipenuhi dengan hiasan bunga atau batu permata. 
Menurut Ali Hanafiah, busana pengantin adat Palembang dipengaruhi oleh negara asing atau budaya asing (Hanafiah, wawancara pribadi, 6 Mei 2021). Letak geografis Palembang juga mempengaruhi masuknya budaya asing atau asing, dan Palembang dulu menyediakan banyak pelabuhan bagi pedagang asing termasuk Jawa, Cina dan Arab pada masa Kerajaan Sriwijaya. Dengan kehadiran orang luar di Palembang, budaya Palembang sangat dipengaruhi oleh budaya luar. Tak terkecuali pada busana pengantinnya yakni Aesan Gede.

Pada busana pengantin Aesan Gede ini tidak hanya sebagai pakaian saja melainkan sebagai wujud nilai budaya yang terealisasikan. Pada busana Pernikahan ini memiliki banyak nilai budaya yang terkandung didalamnya. Berikut ini akan dipaparkan Busana Aesan Gede.

\section{Kain Songket}

Kain songket merupakan kain yang sangat familiar di kalangan masyarakat Indonesia. Kain Songket dengan benang emasnya mampu mengikat dunia. Kain Songket dipergunakan untuk memperindah tampilan si mempelai. Dalam Songket sendiri mengandung unsur visual yang terwujud dalam pola geometris (garis) yang bersifat abstrak. Adapun Songket biasanya memuat wujud benda-benda yang ada di alam (Sunaryo, 2009: 19). Hal ini selaras dengan buku Variety of Indonesia. Kain Songket juga dapat berbentuk pola garis zig-zag atau garis lurus saling bersisi yang mana berarti masyarakat Palembang memiliki sifat keramahan, saling menghargai dan menjaga ketertiban (Sunaryo, 2009: 32).

Sama halnya dengan yang terkandung dalam buku Variety of Indonesia, batik dengan motif batik dan tentu sangat popular (Hoop, 1949: 28). Karena pada motif ini melambangkan rasa persahabatan dan saling menghargai sesama manusia (Sunaryo, 2009: 32). Maka Songket melambangkan keramahtamahan dan saling menghargai satu sama lain pada masyarakat Palembang.

\section{Celana Sutra}

Celana Sutra merupakan celana berukuran panjang yang terbuat dari benang sutra. Celano sutra ini adalah celana panjang yang terbuat dari sutra. Ada sulaman seperti bunga di bagian bawah celana, dan gagangnya panjang atau menyebar. Dalam buku "Dekorasi Nusantara", bentuk bunga dengan batang yang panjang atau bentuk yang menyebar disebut dengan pola merambat. 
Menurut (Sunaryo, 2009; 159) Pola sulur merupakan susunan tumbuhan. Pola sulur melambangkan kebahagiaan dan keberuntungan. Pada pola ini mengandung sebuah harapan untuk menjadi yang lebih baik di masa depan. Seperti dalam buku Ornamen Indonesia, menggambarkan motif sulur ini sebagai bunga yang mempunyai tangkai dan menyebar ke berbagai sisi. Namun dalam buku "Seni Rupa dan Design Islam” Pola Sulur Kerajaan Minangkabao / Pagaruyong dikenal dengan pola ragam hias Aka Bapilin. Menurut tradisi Islam, pola ragam hias Bapilin Aka ini menjadi lebih abstrak. Tema dekoratif alias bapilin bisa diartikan alias menunjukkan akar dan penyebab. Oleh karena itu pola ragam hias ini (disebut juga bapilin) mempunyai makna simbolik yaitu cara berpikir masyarakat Minangkabau sangat gigih dimanapun mereka berada (Setyawati, 2009: 72-73). Dengan cara ini, kedua mempelai akan memiliki kebahagiaan dan keberuntungan setelah menikah.

\section{Dodot}

Dodot merupakan kain yang juga memiliki pola hampir sama dengan Kain Songket yaitu pola geometris dengan ciri zig-zag. Ini melambangkan bahwa kedua mempelai merupakan orang Palembang yang memiliki sifat ramahtama terhadap sesama dan juga saling menghargai.

\section{Jubah}

Jubah ini adalah semacam pengekangan dalam bahasa Arab. Gamis ini berbentuk gaun dengan ukuran besar dan dipenuhi dengan bunga. Pada Jubah ini terdapat bunga teratai yng berada di atas air. Dalan seni Buddha di India, Teratai merupakan subjek yang paling familiar digunakan untuk melambangkna keagungan, kesucian dan rasa cinta terdalam (Sedyawati, 2009: 48) Pola ragam hias teratai merupakan simbol kesucian dan kesucian (Sedyawanti, 2009: 154). Dimaksud pada motif bunga ini pengantin laki-laki yang bahagia atau merasakan senang karena telah menikah.

\section{Rompi/Jas}

Pada busana Aesan Gede, Rompi digunakan oleh mempelai pria. Dalam rompo sendiri memiliki motif tanaman kuncup dibagian dada dan terbwntuk dengan pola zigzag. Pola batang tanaman disebutkan bahwa manusia harus bermanfaatvuntuk manusia lainnya (Sunaryo, 2009: 32) Selain itu, garis zigzag dimaknai dengan simbol persahabatan, keteraturan serta rasa saling menghargai dengan sesama. Karenanya, hal 
ini merupakan awal baru bagi kedua mempelai untuk berperan dalam menyelenggarakan kehidupan keluarga dan menjaga keharmonisan.

\section{Baju Kurung}

Pakaian khas gaya Melayu dengan corak Islam yakni baju kurung tentunya menjadi pakaian dasar untuk mempelai perempuan dalam busana Aesan Gede. Baju kurung ini memiliki motuf yang hampir sama dengan pakaian milik pria namun lebih ditutupi dengan bunga. Itu melambangkan bahwa pengantin wanita juga merasakan kegembiraan dalam pernikahan kedua.

\section{Kesuhun Mempelai Pria}

Kesuhun pria ini memiliki dua corak ragam hias yaitu: ragam hias cemen serta ditambahkan dengan motif bunga. Menurut Sunaryo; 2009 Pola Cemen ini identik dengan mempelai pria sebab cemen merupakan nama lain dari alat kelamin laki-laki. Tugas utama seorang pria adalah melindungi keluarga dan masyarakatnya. Pola ragam hias semen melambangkan bahwa manusia harus memiliki sifat pemberani. Diharapkan laki-laki Palembang mampu membela tanah Palembang dan juga keluarga. Kedua, pola ragam bunga yang terdapat pada kesuhun ini, yaitu pola ragam hias bunga mawar. (Toekio, 2000) mengatakan Pola dekorasi mawar sebagai simbol kesucian dan keanggunan.

\section{Kesuhun Mempelai Wanita}

Pola hias yang termasuk di sini adalah pola cemen serta ditambah dengan ornen bunga. Motif cen merupakan salah satu cara lahir dari motif alat kelamin wanita. Menurut (Sedyawati, 2009: 54) Motif ini diartikan sebgai asal kelahiran dan dianggap sebuah penghormatan dan penghargaan kepada perempuan yang telah menjadi sosok pusat kehidupan. Selain Cen, adanya motif bunga mawar. Jika dikaitkan dengqn daerah Kalimantan Barat, motif bunga ini memberikan arti kekeluargaan (Sunaryo, 2008: 155). Dan berkmakna bahwa perempuan pastinya memiliki sifat keibuan, lembht dan memiliki rasa kekeluargaan yang tinggi.

\section{Tebeng Malu}

Tebeng Malu merupakan penutup kepala bagian samping. Menurut (Syarofi, 2007: 40) tebeng malu digunakan supaya pengantin tidak lirik-lirikan satu sama lain, apalagi berbicara selama di atas pelaminan karena dianggap tabu. 


\section{Pending}

Dalam busana pengantin adat Palembang, Ikat pinggang disebut dengan Pending. Pada pending berpola tumbuhan menjalar, yang bermakna sebagai suatu harapan tentang kehidupan mendatang yang senantiasa selalu baik dan bahagia (Sunaryo, 2009: 158) Jadi ini berarti bahwa kedua calon pengantin sudah siap menjalani kehidupan bersama dan memiliki harapan satu sama lain.

\section{Selendan motif Pelangi}

Pada Selendang Pelangi terdapat dua motif geometris yaitu pola horizontal dan poka lengkung. Menurut Toekio, (2000: 29), pola lengkung bermakna rasa kebahagian atau perasaan senang, sedangkan garis horizontal bermakna rasa tenang. Sehingga Selendang Pelangi berarti bahwa orang-orang Palembang hendaknya merasakan rasa bahagia dan tenang dalam lingkungan bermasyarakat.

\section{Kelapo Setandan}

Kelapo Setandan merupakan sebuah nama untuk menyebut hiasan bunga teratai yang terdapat dibagian kepala pengantin perempuan. Dalam kepercayaan Keraton Cirebon disebutkan bahwa bunga teratai merupakan simbol yang melambangkan kebesaran dan ketatanegaraan. Pada kepercayaan agama Budha, bunga ini dipercayai sebagai suatu yang murni meski teratai muncul dari dalam lumpur. Dalam adat Palembang, Hiasan bunga Teratai beserta tangkainya berjumlah tujuh buah yang bermakna Pikiran, Rasa, Penglihatan, rasa kebijaksanaan, rasa sadar, agung, dan murni.

\section{Ketu}

Yang dimaksud ketu yaitu sejenis mahkota yang berbentuk topi yang dikenakan oleh pengantin laki-laki. Pada bagian depan ketu ini memiliki bentuk pola geometris seperti objek alam. Sedangkan pada bagian mmenyamping terdapat motif pola bunga cempakk dan pada bagian atasnya seperti taburan bunga-bunga teratai. Adapun menurut Toekio, hiasan berbentuk alam tadi memiliki arti nilai keestetikan dan rasa cinta. Sedangkan pola bunga teratai dan cempako melambangkan nilai agung dan suci. Jadi pada Ketu ini berarti pengantin laki-laki memiliki rasa cinta terhadap Tanah asal (Palembang) dan rela untuk membelanya. 


\section{Mahkota Pak Sangkong}

Mahkota Pak Sangkong merupakan mahkota / hiasan kepala bagian dahi yang diikat ke belakang. Dalam mahkota Pak Sangkong ini memuat pola hias teratai dan bunga mawar, dengan pola dasar berbentuk lingkaran. Yang mana pada ketiga pola ini melambangkan rasa kebesaran, kesucian dan rasa cinta.

\section{Fungsi Pakaian Aesan Gede sebagai Wujud Budaya Masyarakat Palembang}

Membahas mengenai fungsi pastinya akan kuat kaitannya dengan suatu manfaat. Fungsi akan terikat dengan manfaat yang terdapat dalam sebuah sistem atau apa yang dihasilkan terhadap sistem yang lainnya. Seperti pada ulasan pendahuluan yang membahas mengenai fungsi dari pakaian, selain memiliki fungsi untuk menutupi dan melindungi bagian tubuh juga berfungsi untuk menambah keindahan. Yang mana kita ketahui bahwasanya manusia merupakan mahkluk yang menyukai keindahan pastinya menjadikannya sebagai suatu kebutuhan. Hal ini yang membuat adanya pola keterkaitan antara manfaat dengan kebutuhan pada kehidupan manusia. Adapun pendapat Gustami dalam (Sunaryo, 2009: 3) Yang dimaksud dengan Ornamen yakni sebuah hasil dari citra, rasa, dan karsa manusia agar bertujuan menjadi sebuah hiasan. Hiasan inilah yang akan menambah nilai keindahan suatu produk benda yang dibuat. Menurut Sunaryo (2009: 4) fungsi ornamen atau hiasan sebagai berikut:

\section{Fungsi Ekstetika}

Fungsi ekstetika adalah fungsi hiasan yang menambah niali keindahan (estetik) penampilan suatu produk sehingga menjadi karya seni yang dapat dinikmati. Dalam hal ini contohnya yaitu hiasan keramik, hasil anyaman, kain tenun, lukisan, perabot rumag tangga dan pahatan.

\section{Fungsi Nilai Simbolis}

Dalam fungsi nilai simbolis ini dapat diamati pada karya seni adat atau bendabenda pusaka yang dianggap memiliki nilai kebesaran yang tentunya bercampur dengan nilai keindahan. Dalam menelaah makna nilai suatu karya harus berdasarkan landasan teori yang jelas dan signifikan agar dapat menemukan hubungan antara nilai keagungan dan juga nilai kemuliaan didalamnya.

Seperti telaah yang dilakukan penulis dalam menemukan fungsi Pakaian Aesan Gede sebagai perwujudan budaya masyarakat Palembang yakni terdiri atas dua fungsi 
utama. Fungsi uang pertama yaitu nilai ekstetika karena Aesan Gede membuat tampilan pengantin menjadi indah dan tak hanya memperindah tetapi juga memiliki segudang makna yang merupakan suatu harapan masyarakat Palembang terhadap kedua mempelai. Kemudian yaitu Aesan Gede berfungsi sebagai nilai simbolis yang terkandung sebab Aesan Gede bukan hanya sebuah busana pengantin tetapi juga merupakan adat budaya yang dibuat oleh masyarakat Palembang dan didasari atas kepercayaan mereka. Sehingga pada akhirnya busana Aesan Gede dianggao sebagai sesuatu yang megah dan bernilai tinggi.

\section{Nilai Budaya Masyarakat Palembang yang terkandung dalam Pakaian Aesan Gede}

Menurut pendapat (Koentjaraningrat, 1985), nilai-nilai budaya ada dalam bentuk gagasan masyarakat tentang hal-hal yang mereka anggap sangat berharga dalam kehidupan, sehingga ditinggalkan sebagai pedoman perilaku manusia. Nilai Budaya merupakan suatu sistem sturan yang terorganisir dan dapat menghasilkan sebuah pilihan dan menetralisir permasalahan yang terjadi di dalam kehidupan bermasyarakat. Adapun nilai ini diwujudkan kedalam sikap dan karakteristik masyarakat yang dibutuhkan oleh budaya (Dewantara, 1994; Direktorat Sejarah Nilai Tradisional, 1992; Rosyadi, 2012). Keyakinan dan nilai berkontribusi pada perkembangan dan sikap. Sikap merupakan kecenderungan yang diperoleh dengan belajar merespon suatu objek secara konsisten. Hal ini juga didukung oleh Mulyana (2007: 52) bahwa sikap ini dipelajari dalam konteks budaya. Nilai-nilai ini biasanya normatif, karena menjadi acuan bagi budayawan tentang apa yang baik dan buruk, benar dan salah.

Peneliti menggunakan konsep nilai di atas untuk menganalisis nilai budaya yang terkandung dalam ragam hias Isanged dalam pernikahan adat Palembang. Nilai-nilai yang dibahas antara lain: nilai yang berhubungan dengan ketuhanan (nilai religius), nilai yang berhubungan dengan orang lain (nilai sosial) dan nilai yang berhubungan dengan diri sendiri (nilai pribadi) (Darsono, 2004). Nilai budaya yang terkandung dalam pakaian dan aksesoris Aesan Gede yaitu:

\section{Nilai Ketuhanan}

Ini adalah nilai-nilai atau pedoman, prinsip-prinsip pedoman yang terkait dengan Sang Pencipta dalam kehidupan manusia. Nilai religi dari pakaian Aesan Gede dapat 
ditemukan di "Saputangan Gobang". Artinya, pasrah dan patuh pada sikap religius. Selain itu juga mengandung ketaatan untuk menutupi auratnya dengan lawan jenisnya yyang bukan merupakan mahramnya. Tebeng malu memiliki nilai religius, artinya manusia harus menjaga pendapatnya sendiri.

\section{Nilai Sosial}

Ini adalah sesuatu yang bernilai, menjadi pedoman dalam hidup manusia, bagaimana berperilaku dan menjadi orang yang baik. Temukan nilai-nilai pribadi di Seneira dalam bentuk semangat dan harapan. Selain itu, celana sutra adalah salah satu bentuk kelembutan. Kesuhun memiliki nilai kebijaksanaan. Gandik memiliki nilai berupa rasa tenang baik dalam hati maupun pikiran. Sedangkan kain Songket bermakna percaya diri.

\section{Nilai Kemasyarakatan}

Ini dianggap sebagai hal yang berharga, mengatur perilaku manusia atau berfungsi sebagai pedoman untuk menjalin hubungan dengan manusia. Nilai-nilai sosial yang terkandung dalam pakaian dan dekorasi Aesan Gede antara lain: sifat ramah yaitu tali kelapa memiliki nilai sosial berupa kelas sosial, gelang ceper, gelang sempuru, gelang ulo betapo memiliki kesatuan, saling menguatkan dan harmonis. Kain songket memiliki nilai kelembutan. Kesuhun mengandung nilai membantu, sedangkan Cempako mengandung nilai sosial menjaga keharmonisan hidup.

\section{Kesimpulan}

Bentuk gaun pengantin Aesan Gede terbagi atas kepala, badan, tangan dan kaki. Dekorasi meliputi pola hias geometris, pola hias tumbuhan, dan pola hias hewan. Pada pola geometris terbagi menjadi dua yaitu horizontal dan lengkung. Pola horizontal dimaknai dengan ketenangan sedangkan untuk pola lengkung menandakan kebahagiaan didalamnya. Pola hias tumbuhan berarti sesuatu yang alami dan berarti mencintai asalnya. Fungsi dekorasi busana Aesan Gede memiliki dua fungsi. Fungsi pertama dekor sebagai fungsi estetika, dan fungsi kedua dekor sebagai fungsi simbolik. Dalam hal ini Aesan Gede bukan hanya sebagai pakaian adat tetapi juga sebagai bentuk ekspresi masyarakat Palembang. 


\section{Daftar Rujukan}

Darsono, Prawira. (2004). Pengantar Estetika. Bandung: P. Rekayasa Sains.

Dewantara, Ki Hadjar. (1994). Kebudayaan. Yogyakarta: Percetakan Ofset Taman Siswa.

Direktorat Sejarah Nilai Tradisional, (1992). Kongres Budaya; Daya dan Cipta Perkembangan Budaya. Jakarta: Departemen Pendidikan Budaya.

Hikmawati, E. (2017). Makna Simbol dalam Aesan Gede dan Pak Sangkong Pakaian Adat Pernikahan Palembang. Jurnal Intelektualita: Keislaman, Sosial dan Sains, 6(1), 1-12.

Hoop, Van Der. (1949). Ragam Perhiasan Indonesia. Batavia: Bataviaasch.

Koentjaraninggrat. (1996). Pengantar Antropologi 1. Jakarta: Rieneka Cipta.

Mutia, Riza. (1996). Pakaian Penghulu Minangkabau. Sumatera Barat: Proyek Pembinaan Permuseuman.

Rosyadi, Ulin Nuha. (2012). Kekayaan Seni Budaya Bangsaku. Bekasi: Aranca Pratama.

Saragih, Meriati S. dkk. (2001). Perlengkapan Upacara Daur Hidup Masyarakat Palembang Koleksi Museum Balaputra Dewa. Palembang: Dinas Pendidikan Nasional Propinsi Sumatera Selatan.

Saramat, Darwis. (1997). Bunga Rampai Adat-Istiadat. Jakarta: Pusat Penelitian Sejarah dan Budaya. Jakarta: Departemen Pendidikan dan Kebudayaan.

Sedyawati, Edi dkk. (2009). Sejarah Kebudayaan Indonesia Seni Rupa dan Desain. Jakarta: Rajawali Pers.

Shanie, A., Sumaryanto, T., \& Triyanto, T. (2017). Busana Aesan Gede dan Ragam Hiasnya sebagai Ekspresi Nilai-Nilai Budaya Masyarakat Palembang. Catharsis, 6(1), 49-56.

Sunaryo, Aryo. (2009). Ornamen Nusantara: Kajian Khusus tentang Ornamen Indonesia. Semarang: Dahara Prize.

Tifanny, V., Rizali, N., \& Rudiyanto, G. (2019). Busana Pengantin Aesan Gede (Tenun Songket dan aksesoris) pada Upacara Pernikahan Adat Palembang Sumatera Selatan. Jurnal Seni dan Reka Rancang: Jurnal Ilmiah Magister Desain, 1(2), 213-222.

Toekio, M. Soegeng. (2000). Mengenal Ragam Hias Indonesia. Bandung: Angkasa.

Zed, Mestika. (2014). Metode Penelitian Kepustakaan. Jakarta: Yayasan Pustaka Obor Indonesia. 